\title{
Casein phosphopeptide combined with fluoride enhances the inhibitory effect on initial adhesion of Streptococcus mutans to the saliva-coated hydroxyapatite disc
}

\author{
Xiaodie Wang ${ }^{1,2}$, Limin Liu ${ }^{1,2}$, Xiaoyan Zhou ${ }^{3}$, Yongbiao Huo ${ }^{1,2}$, Jinlong Gao ${ }^{3,4^{*}+}$ and Haijing Gu $u^{1,2^{*}+}$
}

\begin{abstract}
Background: Recent preventive strategies for dental caries focus on targeting the mechanisms underlying biofilm formation, including the inhibition of bacterial adhesion. A promising approach to prevent bacterial adhesion is to modify the composition of acquired salivary pellicle. This in vitro study investigated the effect and possible underlying mechanism of pellicle modification by casein phosphopeptide (CPP) on Streptococcus mutans (S. mutans) initial adhesion, and the impact of fluoride on the efficacy of CPP.

Methods: The salivary pellicle-coated hydroxyapatite (s-HA) discs were treated with phosphate buffered saline (negative control), heat-inactivated 2.5\% CPP (heat-inactivated CPP), 2.5\% CPP (CPP) or 2.5\% CPP supplemented with $900 \mathrm{ppm}$ fluoride $(C P P+F)$. After cultivation of $\mathrm{S}$. mutans for $30 \mathrm{~min}$ and $2 \mathrm{~h}$, the adherent bacteria were visualized by scanning electron microscopy (SEM) and quantitatively evaluated using the plate count method. Confocal laser scanning microscopy (CLSM) was used to evaluate the proportions of total and dead S. mutans. The concentrations of total, free, and bound calcium and fluoride in the CPP and fluoride-doped CPP solutions were determined. The water contact angle and zeta potential of s-HA with and without modification were measured. The data were statistically analyzed using one-way ANOVA followed by a Turkey post hoc multiple comparison test.

Results: Compared to the negative control group, the amount of adherent S. mutans significantly reduced in the CPP and CPP + F groups, and was lowest in the CPP + F group. CLSM analysis showed that there was no statistically significant difference in the proportion of dead $\mathrm{S}$. mutans between the four groups. Water contact angle and zeta potential of s-HA surface significantly decreased in the CPP and CPP + F groups as compared to the negative control group, and both were lowest in the CPP + F group.

Conclusions: Pellicle modification by CPP inhibited S. mutans initial adhesion to s-HA, possibly by reducing hydrophobicity and negative charge of the s-HA surface, and incorporating fluoride into CPP further enhanced the anti-adhesion effect.
\end{abstract}

Keywords: Casein phosphopeptide, Fluoride, Bacterial adhesion, Salivary pellicle, Dental caries, Streptococci mutans

\footnotetext{
*Correspondence: jinlong.gao@sydney.edu.au; guhj@mail.sysu.edu.cn

† Jinlong Gao and Haijing Gu contributed equally to this work.

${ }^{3}$ School of Dentistry, Faculty of Medicine and Health, The University of Sydney, Camperdown, NSW, Australia

${ }^{1}$ Hospital of Stomatology, Guanghua School of Stomatology, Sun Yat-sen University, 56 Ling Yuan Xi Road, Guangzhou 510055, Guangdong, China Full list of author information is available at the end of the article
}

(c) The Author(s). 2020 Open Access This article is licensed under a Creative Commons Attribution 4.0 International License, which permits use, sharing, adaptation, distribution and reproduction in any medium or format, as long as you give appropriate credit to the original author(s) and the source, provide a link to the Creative Commons licence, and indicate if changes were made. The images or other third party material in this article are included in the article's Creative Commons licence, unless indicated otherwise in a credit line to the material. If material is not included in the article's Creative Commons licence and your intended use is not permitted by statutory regulation or exceeds the permitted use, you will need to obtain permission directly from the copyright holder. To view a copy of this licence, visit http://creativecommons.org/licenses/by/4.0/ The Creative Commons Public Domain Dedication waiver (http://creativecommons.org/publicdomain/zero/1.0/) applies to the data made available in this article, unless otherwise stated in a credit line to the data. 


\section{Background}

Dental caries is a biofilm-mediated multifactorial disease $[1,2]$. The formation of dental biofilm is initiated by bacterial adhesion to the acquired salivary pellicle on the surface of dental hard tissues [3]. Salivary pellicle is formed immediately after toothbrushing through the selective adsorption of salivary components onto the tooth surface. The pellicle has a protective effect against dental caries by functioning as a semi-permeable barrier, and a calcium and phosphate reservoir to concurrently regulate calcium and phosphate homeostasis between tooth surface and saliva, inhibiting demineralization and promoting remineralization [3]. However, the amylase and proline-rich proteins presented in the pellicle also serve as specific binding sites for lectin-like bacterial adhesins, thereby facilitating bacterial adhesion to the pelliclecoated tooth surface [4]. The primary cariogenic bacterium Streptococcus mutans (S. mutans) has been shown to colonize on the tooth surface via the interaction with the salivary pellicle [5]. Conventional treatment of biofilm-related diseases aims at the mechanical removal of the biofilms. Recent therapeutic strategies focus on targeting the mechanisms underlying biofilm formation, including the inhibition of bacterial adhesion [6]. The alteration of molecular composition and physicochemical properties of the pellicle has been shown to disrupt the bacterial adhesion [7]. For example, modification of the pellicle by natural products, such as tannic acid and propolis, is considered to be a safe and cost-effective approach to prevent bacterial adhesion $[8,9]$.

Casein phosphopeptide (CPP) is milk-derived phosphorylated peptide that can be naturally present in milk or obtained by proteolytic digestion of casein [10-12]. CPP contains the cluster sequence -Ser(P)-Ser(P)-Ser $(\mathrm{P})$ Glu-Glu- which is a high polar acidic domain with high binding affinity for divalent metal ions [13]. CPP has been shown to bind and solubilize calcium efficiently, enhance the absorption of calcium in the gastrointestinal tract, improve remineralization of the tooth surface, and buffer the $\mathrm{pH}$ of dental biofilm [14]. Previous studies have also demonstrated the efficacy of CPP on inhibiting demineralization [15] and promoting remineralization [16] of non-carious lesion in vitro. A randomized controlled trial showed that toothpaste containing 2\% CPP or $1190 \mathrm{mg} / \mathrm{kg}$ fluoride similarily reduced the incidence of caries [17]. The caries-preventive activity of CPP is attributed to its ability to stabilize high levels of amorphous calcium phosphate (ACP) on the tooth surface [18], and the CPP-amorphous calcium phosphate (CPP-ACP) complex has been developed and patented by the Reynolds group [19]. However, limited information is available on the effect of CPP on bacterial activity. 0.5\% CPP solution had no significant effect on the established $S$. mutans biofilm [20]. Previous research indicated that
CPP inhibited S. mutans and Streptococcus sobrinus (S. sobrinus) initial adhesion to the pellicle-coated hydroxyapatite surface [21]. However, the exact anti-adhesion mechanism of CPP remains unknown.

Fluoride has been recognized as an anti-caries agent over seven decades. Fluoride can inhibit demineralization and promote remineralization of dental hard tissues [22]. Fluoride also inhibits bacterial glycolytic enzyme and mediates transmembrane proton movement, which leads to bacterial cytoplasmic acidification and even kills the bacteria [23]. It has been proposed that incorporating fluoride as a phosphatase inhibitor into the $\mathrm{CPP}$-containing dental care products can enhance the effectiveness of CPP during application [24]. Although several studies showed that incorporating fluoride into CPP-ACP further improves the remineralization efficacy of CPP-ACP [25, 26], there were also evidences indicating that incorporating fluoride into CPP or CPP-ACP did not improve their demineralization-suppressing effect $[15,18,27,28]$. The impact of fluoride on the efficacy of CPP remains unclear.

The aim of this study was to investigate the effect and possible underlying mechanism of CPP on pellicle modification and $S$. mutans initial adhesion, as well as the impact of fluoride on the efficacy of CPP.

\section{Methods}

\section{Casein phosphopeptide and fluoride}

CPP powder (Fujifilm Wako Pure Chemical Corporation, Osaka, Japan) and sodium fluoride (Sigma, Saint Louis, MO, USA) used in this study were reagent-grade.

\section{Test solutions}

Two-fold serially diluted CPP solutions in the range of $0.15625-10 \%(\mathrm{w} / \mathrm{v})$ and $2.5 \%$ CPP solution supplemented with $900 \mathrm{ppm}$ fluoride were prepared. After adjusting the $\mathrm{pH}$ to 7.0 using sodium hydroxide, the solutions were sterilized through a $0.22 \mu \mathrm{m}$ polyethersulfone membrane (Merck Millipore Ltd., Tullagreen, Carrigtwohill, Co. Cork, IRL). Heat-inactivated 2.5\% $\mathrm{CPP}$ solution was prepared by autoclaving at $121{ }^{\circ} \mathrm{C}$ for $15 \mathrm{~min}$. All solutions were prepared freshly and used on the same day.

\section{Hydroxyapatite disc}

Hydroxyapatite (HA) disc $(9.7 \mathrm{~mm}$ in diameter and 1.5 $\mathrm{mm}$ in thickness, Clarkson Chromatography Products, South Williamsport, PA, USA) was used as the substrate in this study. To visualize the live and dead bacteria cells on the substrate surface, the HA disc was polished using a precision lapping/polishing machine (Unipol-1502, Kejing Auto-Instrument Co., LTD, Shenyang, China) with FEPA P \#500, \#1200, and \#2000 silicon carbide 
sandpapers under constant water cooling, until the disc reached a thickness of $0.3 \mathrm{~mm}$. After polishing, the disc was sonicated in ultrapure water for $10 \mathrm{~min}$ to remove the debris. Before experiments, the HA disc was autoclaved at $121^{\circ} \mathrm{C}$ for $15 \mathrm{~min}$.

\section{Bacterial strain and culture conditions}

S. mutans UA159 (ATCC 700610) purchased from Guangdong Microbial Culture Collection Center was used in this study. To prepare the inoculum, S. mutans was firstly recovered on a brain heart infusion (BHI, Difco, Detroit, MI, USA) agar plate supplemented with $5 \%$ sterile defibrinated sheep blood for $48 \mathrm{~h}$ at $37^{\circ} \mathrm{C}$ under anaerobic conditions $\left(5 \% \mathrm{CO}_{2}, 10 \% \mathrm{H}_{2}, 85 \% \mathrm{~N}_{2}\right)$. A single colony was selected and inoculated into $10 \mathrm{~mL}$ of BHI broth and incubated anaerobically at $37^{\circ} \mathrm{C}$ overnight. Bacteria was harvested by centrifugation (3000 $\mathrm{rpm}, 4^{\circ} \mathrm{C}, 5 \mathrm{~min}$ ), washed twice with sterile phosphate buffered saline (PBS), and finally re-suspended in BHI broth. The optical density at $600_{\mathrm{nm}}\left(\mathrm{OD}_{600 \mathrm{~nm}}\right)$ was adjusted to 0.2 (corresponding to a concentration of approximately $2.0 \times 10^{8}$ cells $/ \mathrm{mL}$ ).

\section{Saliva collection and preparation}

Human whole unstimulated saliva was collected from eight healthy volunteers ( 5 females and 4 males; age range 21-27 years; mean ange $24.2 \pm 2.0$ ) recruited from students of dental faculty. The exclusion criteria include patients with systemic diseases, salivary gland disorders, active caries or periodontal disease, smoker, antibiotics or antibiotics-containing mouthwashes uses for the last 3 months before saliva collection. The aim and details of saliva collection were explained, such as not taking in anything for at least $2 \mathrm{~h}$ before saliva collection, and informed consent was obtained from all volunteers. The present study was approved by the Ethical Review Committee, Hospital of Stomatology, Guanghua School of Stomatology, Sun Yat-sen University (Approval No. ERC-[2017]-24). Collection and preparation of the saliva samples were performed referring to several published methods with some modification [29, 30]. Briefly, saliva collection was performed during the morning appointments, and the volunteers were asked to sit in a comfortable position and avoid swallowing or other oral movements during collection. The saliva was spat into a sterile and iced centrifuge tube before they experienced an urge to swallow the pooled saliva in the floor of the mouth. This process was repeated until $10 \mathrm{~mL}$ of whole saliva was obtained, which usually took about 50-60 min. The saliva from eight donors was pooled. After centrifugation at $4000 \mathrm{rpm}$ and $4{ }^{\circ} \mathrm{C}$ for $20 \mathrm{~min}$, the supernatant was collected and filtered using a $0.22 \mu \mathrm{m}$ polyethersulfone membrane. Clarified saliva samples were separated into $12 \mathrm{~mL}$ aliquots, frozen quickly in liquid nitrogen, and stored at $-80{ }^{\circ} \mathrm{C}$. Saliva samples were used within 6 months and thawed at room temperature prior to experiments. Saliva collection from the same donors was carried out with an interval of at least 30 days, until the present study was completed.

\section{Adhesive inhibitory concentration assay}

Fourty-eight HA discs were individually placed into the wells of two 24-well plates (Costar, Corning, NY, USA). A volume of $1 \mathrm{~mL}$ of the clarified saliva was added into each well and incubated at $37^{\circ} \mathrm{C}$ for $2 \mathrm{~h}$. After rinsing twice with sterile PBS to obtain salivary pellicle-coated HA (s-HA) discs, the discs were randomly divided into eight groups ( $n=6$ per group): control group (PBS), and seven CPP groups containing serially diluted concentrations of CPP. The s-HA disc was incubated in $1 \mathrm{~mL}$ of the corresponding solutions for $2 \mathrm{~h}$ at $37^{\circ} \mathrm{C}$, followed by two rinses with PBS. A volume of $1 \mathrm{~mL}$ of the bacteria suspension was seeded and incubated for $30 \mathrm{~min}$ and $2 \mathrm{~h}$ in a humidified atmosphere of $5 \% \mathrm{CO}_{2}$ at $37^{\circ} \mathrm{C}$ (three discs per group and incubation time). After rinsing twice with PBS to remove non-attached and loosely bound bacteria, the HA disc was transferred into an eppendorf tube containing $2 \mathrm{~mL}$ of PBS. Adherent $S$. mutans was detached by sonication for $10 \mathrm{~min}$, followed by vortexing for a further $60 \mathrm{~s}$. The sonicated and vortexed S. mutans suspension was serially diluted and $100 \mu \mathrm{L}$ of the diluted solution was spread over a BHI agar plate and incubated for $48 \mathrm{~h}$ at $37^{\circ} \mathrm{C}$ in a humidified atmosphere of $5 \% \mathrm{CO}_{2}$. The number of adherent $S$. mutans was expressed as colony-forming units (CFU) per disc. The experiment was repeated three times in triplicate. The adhesion reduction percentage was calculated as follows: (CFU counts of the control group - CFU counts of the treated group)/CFU counts of the control group $\times 100 \%$.

\section{Bacterial adhesion assay}

$\mathrm{CPP}$ at $2.5 \%(\mathrm{w} / \mathrm{v})$ was used for further experiments based on the ability to reduce the adhesion of $S$. mutans by approximately $50 \%$ [31]. For the $S$. mutans adherence assay, s-HA disc was prepared as described above. The s-HA discs were randomly divided into four groups $(n=$ 10 per group) and incubated with $1 \mathrm{~mL}$ of PBS (negative control), heat-inactivated $2.5 \%$ CPP (heat-inactivated CPP), 2.5\% CPP (CPP) or 2.5\% CPP supplemented with $900 \mathrm{ppm}$ fluoride $(\mathrm{CPP}+\mathrm{F})$ for $2 \mathrm{~h}$ at $37^{\circ} \mathrm{C}$. Pellicle formation on HA surface and CPP adsorption onto the s-HA surface were determined by measuring the amount of proteins/peptides on the HA disc (see Additional file 1). After rinsing twice with PBS, a volume of $1 \mathrm{~mL}$ of the $S$. mutans suspension was seeded and incubated for $30 \mathrm{~min}$ and $2 \mathrm{~h}$ in a humidified atmosphere of $5 \% \mathrm{CO}_{2}$ at $37^{\circ} \mathrm{C}$ (five discs per group and incubation time). The number of adherent $S$. mutans was measured 
using the plate count method as described above and expressed as CFU per disc. The experiment was repeated three times in triplicate.

Scanning electron microscopy (SEM) was used to visualize $S$. mutans adhesion on the HA surface. Two samples from each group and incubation time were prefixed in $2.5 \%$ glutaraldehyde at room temperature for at least $3 \mathrm{~h}$. After washing four to six times using ultrapure water, samples were dehydrated using gradient concentrations of ethanol $(30,50,70,80,85,90,95$, and $100 \%)$ for $15 \mathrm{~min}$, and then substituted by tert butyl alcohol three times, freeze-dried, sputter-coated with gold, and examined by SEM (JSM-6330F, JEOL, Japan).

\section{Bacteria LIVE/DEAD staining}

Adhesion of S. mutans was also measured using a LIVE/ DEAD BackLight Bacterial Viability Kit (L7012, Thermo Scientific, USA). The polished and sterile HA discs with a thickness of $0.3 \mathrm{~mm}$ were used. s-HA discs were prepared and divided into four groups ( $n=6$ per group) as described above: negative control, heat-inactivated CPP, $\mathrm{CPP}$, and CPP + F groups. After rinsing twice with PBS, 1 $\mathrm{mL}$ of the $S$. mutans suspension was seeded and incubated for $30 \mathrm{~min}$ and $2 \mathrm{~h}$ in a humidified atmosphere of $5 \% \mathrm{CO}_{2}$ at $37^{\circ} \mathrm{C}$ (three HA discs per group and incubation time). The HA disc was washed twice with $0.9 \%$ sodium chloride and then stained with $1 \mathrm{~mL}$ of LIVE/DEAD ${ }^{\circ}$ BacLight $^{\mathrm{Tw}}$ solution at room temperature in the dark for $15 \mathrm{~min}$. A volume of $1 \mathrm{~mL}$ of LIVE/DEAD ${ }^{\circ}$ BacLight $^{\mathrm{mi}}$ solution contained $997 \mu \mathrm{L}$ of ultrapure water, $1.5 \mu \mathrm{L}$ of propidium iodide (PI), and $1.5 \mu \mathrm{L}$ of SYTO 9, which was prepared according to the manufacturer's instructions. Dead bacterial cells with damaged membrane were finally stained in red color by PI, while live bacterial cells with intact cell membrane were stained in green color by SYTO 9. Samples were observed by a confocal laser scanning microscopy (CLSM, LSM 780, Zeiss, Oberkochen, BW, Germany) with a $20 \times$ water-immersion objective lens. Dual-channel scanning observations were performed through a green channel for SYTO 9 (excitation wavelength: $488 \mathrm{~nm}$ ) and a red channel for PI (excitation wavelength: $543 \mathrm{~nm}$ ). Four fields were randomly selected on each sample for scanning. Image analysis was performed with ImageJ software. The ratio of the area occupied by green or red fluorescence to the whole area on each visual field was measured. For each specimen, the ratio (\%) of the area covered by total fluorescence of each color to the whole area was calculated. Subsequently, the proportion (\%) of red to total fluorescence was measured. The experiment was replicated three times in triplicate.

\section{Ion quantified analysis}

The total and free calcium and fluoride concentrations in $2.5 \% \mathrm{CPP}$ and $2.5 \% \mathrm{CPP}$ supplemented with $900 \mathrm{ppm}$ fluoride solutions were quantified, and the corresponding bound ion concentrations were calculated. Before detecting the total ion concentrations, $1 \mathrm{~mL}$ of the initial solution was diluted with $19 \mathrm{~mL}$ of $1.0 \mathrm{M} \mathrm{HNO}_{3}$ and reacted for $24 \mathrm{~h}$, followed by centrifugation at $1000 \mathrm{~g}$ for $15 \mathrm{~min}$ at room temperature; the supernatant was collected to detect the total ion concentration [32]. Before detection of free ion concentrations, macromolecular CPP with a molecular weight of approximately $3 \mathrm{kDa}$ was filtered using a magnetically stirred ultrafiltration device (Amicon, Model 8200, $200 \mathrm{~mL}$, Millipore) equipped with an ultrafiltration disc $\left(1 \mathrm{kDa}\right.$ NMWL, PLAC06210, Ultracel $^{\bullet}$ regenerated cellulose, Millipore). According to the instructions, $50 \mathrm{~mL}$ of the initial solution was added into the device; equipped with a magnetic stirrer at $300 \mathrm{rpm}$, the ultrafiltration separation was driven using high-purity $\mathrm{N}_{2}$ (99.999\%) and the pressure was maintained within $2.4 \mathrm{~atm}$. CPP was filtered and the filtrate was collected to detect the free ion concentrations. Fluoride concentration was detected by ion chromatography (IC-1100, Thermo Fisher Scientific, USA), and calcium concentration was measured using inductively coupled plasma-optical emission spectroscopy (ICP-OES, ICP-OES 730, Agilent, USA). Calcium and fluoride concentrations were expressed as $\mathrm{mmol} / \mathrm{L}(\mathrm{mM})$.

\section{Water contact angle measurement}

s-HA discs were prepared and divided into four groups as described above: negative control, heat-inactivated $\mathrm{CPP}, \mathrm{CPP}$, and $\mathrm{CPP}+\mathrm{F}$ groups. After rinsing twice with PBS, the discs were dried under a stream of nitrogen [33]. Water contact angle was measured with a Contact Angle Meter (DMo-501, Kyowa Kogyo CO., LTD, Japan). The sessile drop technique was employed and deionized water was used as the medium $(2 \mu \mathrm{L}$ per drop). The right and left water contact angles for each droplet were measured at room temperature and averaged. For each sample, the measurement was repeated at three randomly selected regions. Finally, the result was expressed as degree $\left(^{\circ}\right)$.

\section{Zeta potential analysis}

The electrophoretic mobilities of s-HA powder (Clarkson Chromatography Products, Williamsport, PA, USA) with and without modification were measured by a Zeta Potential Analyzer (Zetasizer Nano ZS90; Malvern Instruments, Malvern, UK) according to a published method [34]. The HA powder is the raw material for the HA disc that was used in the current study. Both the HA powder and HA disc were purchased from the same company. s-HA was prepared and divided into negative control, heat-inactivated CPP, CPP, and CPP + F groups as described above in an incubator shaker $(50 \mathrm{rpm})$ at $37^{\circ} \mathrm{C}$. Five measurements of electrophoretic mobilities for each sample were averaged. The zeta potential was 
calculated according to the Helmholtz-Smoluchowski formula and expressed as $\mathrm{mV}$.

\section{Statistical analysis}

For all statistical analyses, SPSS v.19.0 software (IBM, Armonk, NY, USA) was used. All values were expressed as the mean \pm standard deviation (SD). The inter-group differences were estimated by one-way analysis of variance (ANOVA) followed by a Turkey post hoc multiple comparison test. The level of significance was set at $p<0.05$.

\section{Results}

Effect of serially diluted CPP on S. mutans initial adhesion As shown in Fig. 1, at 30 min of incubation, compared with the control group, the reduction in the adhesion of S. mutans was $12.6,36.8,49.6,76.2$, and $82.9 \%$ for the CPP groups at concentrations of 0.63 to $10 \%$, successively and respectively (0.63\% CPP: $p<0.01$; others: $p<0.0001)$. At $2 \mathrm{~h}$ of incubation, the adhesion of $S$. mutans was reduced by $32.9,51.5,78.5$, and $83.8 \%$ for the CPP groups at concentrations of 1.25 to $10 \%$, successively and respectively (all: $p<0.0001$ ). Although the adhesion reduction in the $0.63 \%$ CPP group was $8.9 \%$ at 2 $\mathrm{h}$ of incubation, the difference was not significant ( $p=$ 0.094). There were no significant differences between the $0.16 \% \mathrm{CPP}$, the $0.31 \% \mathrm{CPP}$, and the control groups at $30 \mathrm{~min}$ and $2 \mathrm{~h}$ of incubation.

\section{Effect of CPP and fluoride-doped CPP on S. mutans initial} adhesion to s-HA

The effect of 2.5\% CPP and 2.5\% CPP supplemented with $900 \mathrm{ppm}$ fluoride on the initial adhesion of $S$. mutans to s-HA was visualized by SEM (Fig. 2a) and quantitatively evaluated by the plate count method (Fig. $2 \mathrm{~b})$. The formation of pellicle with CPP on the s-HA surface was confirmed by the bicinchoninic acid (BCA) method (see Additional file 1).

SEM images showed the distribution of $S$. mutans on HA discs with different coatings. The images showed a lower distribution of $S$. mutans in the CPP and CPP + F groups than that in the negative control and heatinactivated CPP groups, both at $30 \mathrm{~min}$ and $2 \mathrm{~h}$, and the $\mathrm{CPP}+\mathrm{F}$ group showed the lowest distribution. Quantitative analysis using the plate count method showed no significant difference between the negative control and the heat-inactivated CPP groups at $30 \mathrm{~min}(p=0.409)$ and $2 \mathrm{~h}(p=0.877)$. At $30 \mathrm{~min}$ of incubation, the CFU counts were 50.8 and $74.0 \%$ lower in the CPP and CPP + $\mathrm{F}$ groups, respectively, than in the negative control group (both: $p<0.0001$ ). The amount of $S$. mutans in the $\mathrm{CPP}+\mathrm{F}$ group was reduced by $47.2 \%$ compared with that in the CPP group $(p<0.0001)$. Similar results were obtained at $2 \mathrm{~h}$ of incubation: the CFU counts were 48.4 and $74.5 \%$ lower in the $\mathrm{CPP}$ and $\mathrm{CPP}+\mathrm{F}$ groups, respectively, than in the negative control group (both: $p<$ $0.0001)$, and $50.6 \%$ lower in the $\mathrm{CPP}+\mathrm{F}$ group than in the CPP group $(p<0.0001)$.

\section{Live and dead staining analysis}

Live and dead staining analysis was performed to confirm the anti-adhesion effect of CPP and fluoride-doped $\mathrm{CPP}$, and to estimate their antimicrobial properties. As shown in Fig. 3a, fluorescence was lower in the CPP and $\mathrm{CPP}+\mathrm{F}$ groups than that in the negative control and
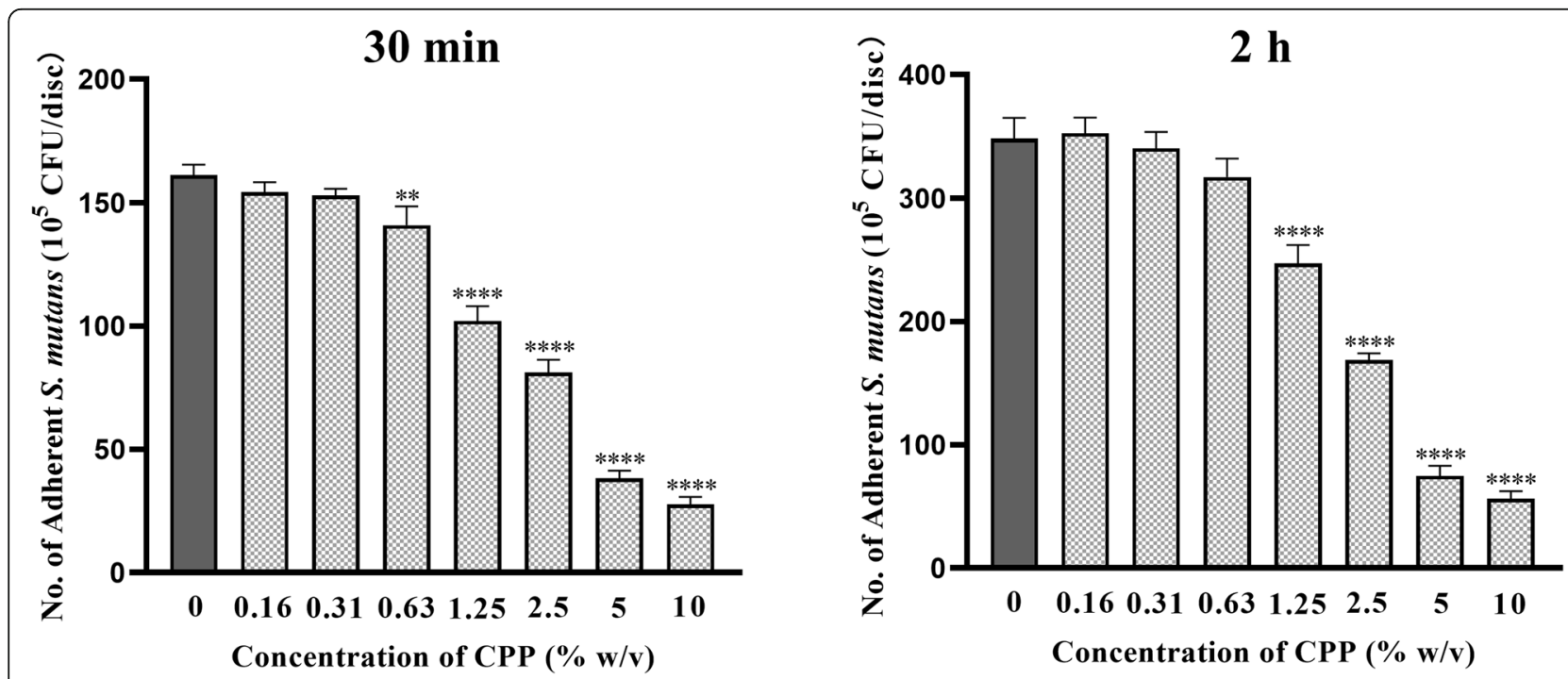

Fig. 1 Effect of different concentrations of CPP on S. mutans initial adhesion. Salivary pellicle-coated HA disc was modified by two-fold serially diluted CPP solutions in the range of $0.15625-10 \%$, followed by cultivation of S. mutans for 30 min and $2 \mathrm{~h}$. Colony forming units (CFU) counts of S. mutans per disc were determined and the results were expressed as the mean \pm SD. ${ }^{* *} p<0.01,{ }^{* * * *} p<0.0001$ compared with the control group 


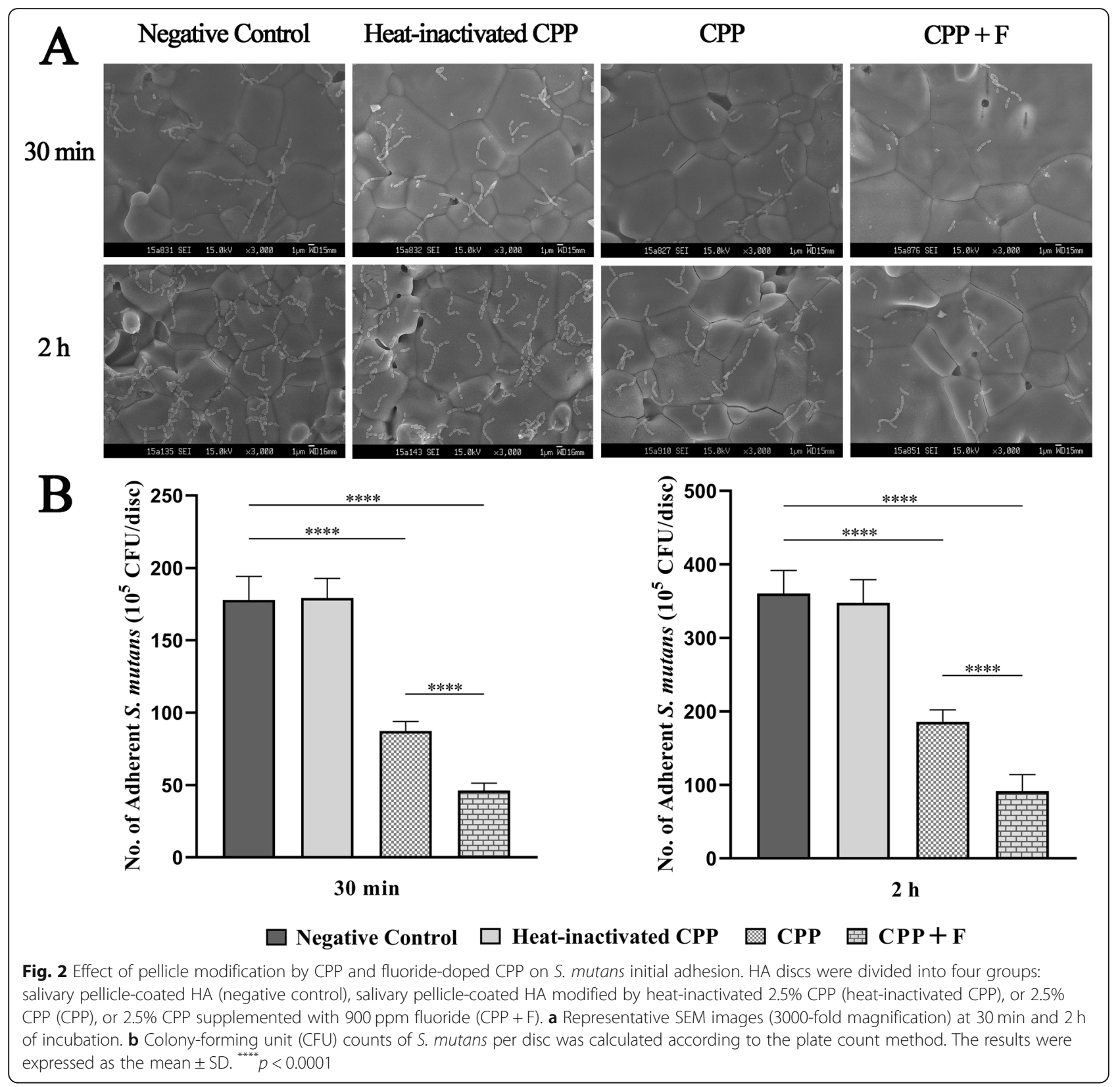

heat-inactivated CPP groups, both at $30 \mathrm{~min}$ and $2 \mathrm{~h}$. The ratio of the area occupied by total fluorescence (total S. mutans) to the whole area for the negative control, heat-inactivated CPP, CPP, and CPP $+\mathrm{F}$ groups was $11.19,11.17,5.46$, and $2.70 \%$ at $30 \mathrm{~min}$ of incubation, and 20.01, 19.84, 9.87, and $4.24 \%$ at 2 $\mathrm{h}$ of incubation, respectively (Fig. $3 \mathrm{~b}$ ). The area (\%) occupied by $S$. mutans in the CPP and CPP $+\mathrm{F}$ groups was $51.23 \%(p<0.001)$ and $75.84 \% \quad(p<$ $0.0001)$ lower at $30 \mathrm{~min}$ and was $50.67 \%(p<0.01)$ and $78.80 \%(p<0.0001)$ lower at $2 \mathrm{~h}$ than that in the negative control group, respectively. The area occupied by $S$. mutans in the CPP + F group was $50.46 \%$ lower at $30 \mathrm{~min}$ and $57.01 \%$ lower at $2 \mathrm{~h}$ than that in the CPP group (both: $p<0.05$ ). There was no significant difference between the negative control and the heat-inactivated CPP groups, both at $30 \mathrm{~min}$ and $2 \mathrm{~h}$ (both: $p=1$ ).

The proportion (\%) of red fluorescence (dead $S$. mutans) to total fluorescence (total S. mutans) was 2.09, $2.23,2.63$, and $2.40 \%$ at $30 \mathrm{~min}$, and 1.61, 1.95, 2.31, and $2.15 \%$ at $2 \mathrm{~h}$, for the negative control, heat-inactivated $\mathrm{CPP}, \mathrm{CPP}$, and $\mathrm{CPP}+\mathrm{F}$ groups, respectively (Fig. 3c). There were no significant differences between the four groups, both at $30 \mathrm{~min}$ and $2 \mathrm{~h}$ (30 min: $p=0.061 ; 2 \mathrm{~h}$ : $p=0.213)$. 

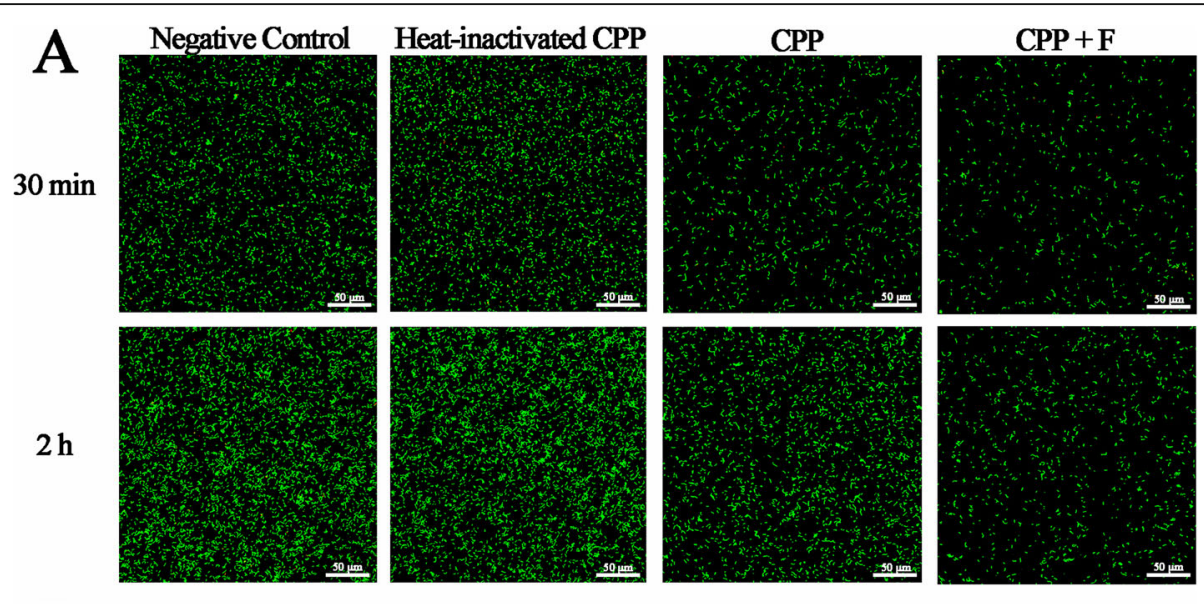

B
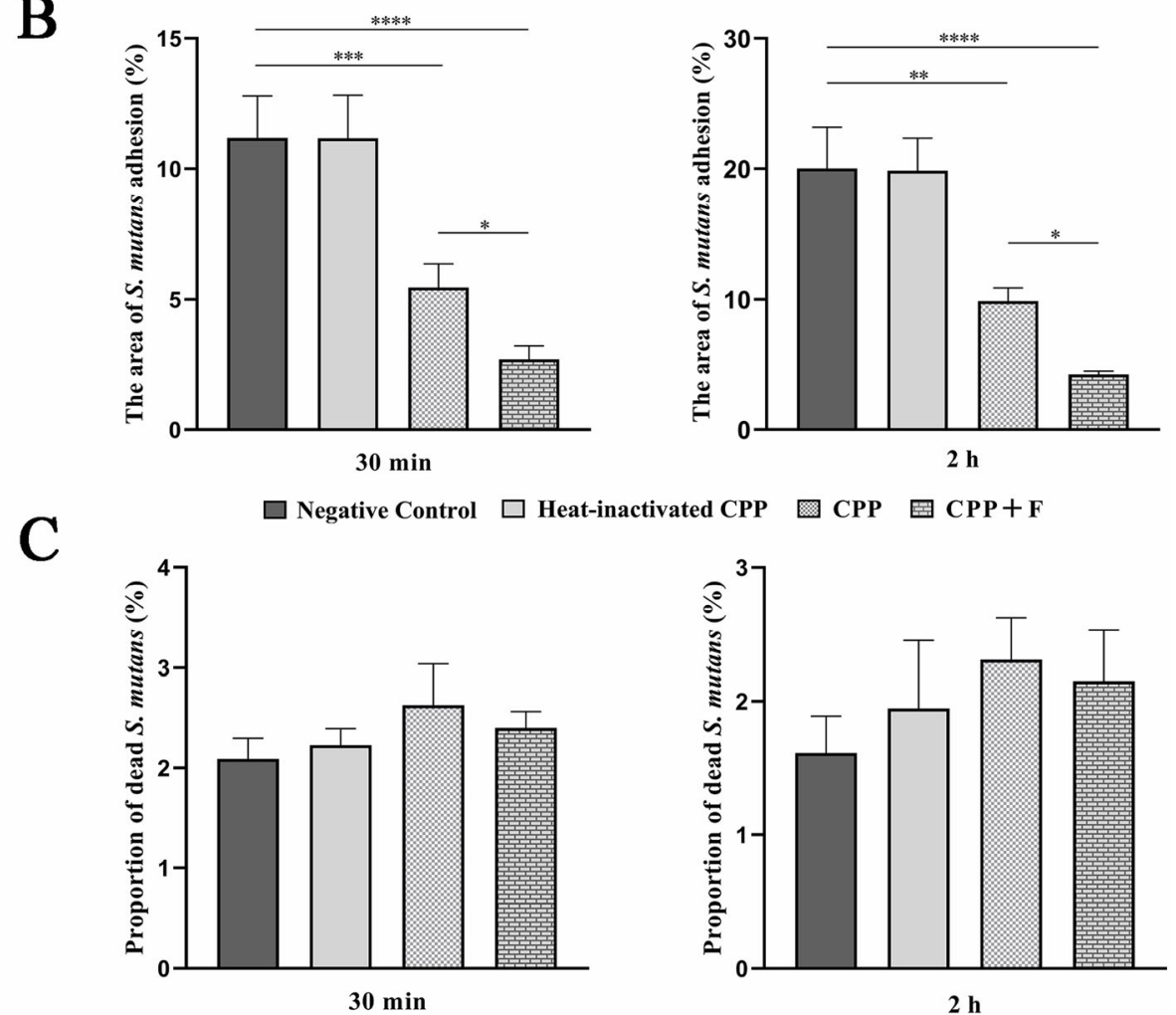

Fig. 3 Live/dead staining analysis of S. mutans initial adhesion to HA discs with different coatings. HA discs were divided into four groups: salivary pellicle-coated HA (negative control), salivary pellicle-coated HA modified by heat-inactivated 2.5\% CPP (heat-inactivated CPP), or $2.5 \%$ CPP (CPP), or 2.5\% CPP supplemented with $900 \mathrm{ppm}$ fluoride (CPP + F). a Representative CLSM images at 30 min and $2 \mathrm{~h}$ of incubation. $\mathbf{b}$ Ratio (\%) of the area occupied by total fluorescence (total S. mutans) to the whole area. c Proportion (\%) of red fluorescence (dead S. mutans) to total fluorescence (total S. mutans). Data were expressed as the mean \pm SD. ${ }^{*} p<0.05,{ }^{* *} p<0.01,{ }^{* * *} p<0.001,{ }^{* * * *} p<0.0001$

\section{Calcium and fluoride concentrations in experimental} solutions

The concentrations of total, free and bound calcium and fluoride in 2.5\% CPP and 2.5\% CPP supplemented with $900 \mathrm{ppm}$ fluoride solutions are shown in Table 1 . The $2.5 \%$ CPP solution ( $\mathrm{pH} 7.0$ ) contained $30.00 \mathrm{mM} \mathrm{Ca}^{2+}$ but not $\mathrm{F}^{-}$endogenously, and majority of the $\mathrm{Ca}^{2+}$ (29.08 mM, 96.9\%) was in the bound form. The $2.5 \%$ CPP solution supplemented with $900 \mathrm{ppm}$ fluoride contained $47.35 \mathrm{mM}$ (899.65 ppm) $\mathrm{F}^{-}$, and $33.75 \mathrm{mM}$ (641.25 ppm, 71.3\%) $\mathrm{F}^{-}$was bound by CPP, and the other was similar to the $2.5 \%$ CPP solution.

\section{Water contact angle measurement}

The results of water contact angle measurement are shown in Table 2, and the representative images are shown in Fig. 4. Water contact angle significantly decreased from $42.0^{\circ}$ (negative control) to $24.1^{\circ}(\mathrm{CPP})$ and 
Table 1 Concentrations of total, free, and bound calcium and fluoride in the experimental solutions

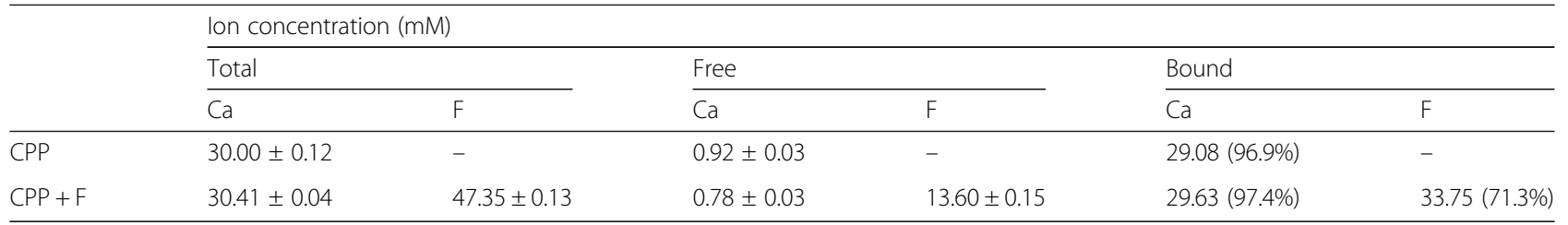

CPP: $2.5 \%$ CPP solution; CPP + F: 2.5\% CPP supplemented with 900 ppm fluoride solution; Ca: Calcium; F: Fluoride. The concentrations of total and free calcium and fluoride in solutions were measured, and the corresponding bound ion concentrations were calculated. Data are expressed as the mean \pm SD. Percent of ion bound by CPP is indicated in parentheses

$17.4^{\circ}(\mathrm{CPP}+\mathrm{F})$ (both: $\left.p<0.0001\right)$, and was smaller in the $\mathrm{CPP}+\mathrm{F}$ group than in the CPP group $(p<0.05)$. The water contact angle was higher in the heat-inactivated CPP group $\left(55.9^{\circ}\right)$ than in the other groups (all: $p<$ 0.0001).

\section{Zeta potential analysis}

All s-HA surfaces with or without modification exhibited negative zeta potential values, and the results are shown in Table 2. The zeta potential value for the negative control group was $-9.8 \mathrm{mV}$, which decreased to -11.5 , 16.4, and $-19.4 \mathrm{mV}$ for the heat-inactivated CPP, CPP, and $\mathrm{CPP}+\mathrm{F}$ groups, respectively (all: $p<0.0001$ ). The value for the $\mathrm{CPP}+\mathrm{F}$ group was significantly lower than that for the CPP group $(p<0.0001)$.

\section{Discussion}

A promising approach to prevent dental caries is to reduce the abundance of $S$. mutans in dental biofilm by interfering with its initial adhesion to tooth surface [33, 35]. Pellicle modification is recognized as an alternative option for improving the anti-adhesion properties of the tooth surface [36]. The present study provides evidence of the anti-adhesion effect of CPP and fluoride-doped CPP on S. mutans.

An in vitro model was established to simulate pellicle formation and modification as well as initial adhesion of S. mutans. We did not perform experiments on natural enamel, because individual enamel specimens had

Table 2 Water contact angle and zeta potential of the HA with different coatings

\begin{tabular}{lll}
\hline & $\begin{array}{l}\text { Water contact } \\
\text { angle (degree) }\end{array}$ & $\begin{array}{l}\text { Zeta potential } \\
(\mathrm{mV})\end{array}$ \\
\hline Negative control & $42.0 \pm 1.1^{\mathrm{a}}$ & $-9.8 \pm 0.2^{\mathrm{a}}$ \\
Heat-inactivated CPP & $55.9 \pm 3.4^{\mathrm{b}}$ & $-11.5 \pm 0.7^{\mathrm{b}}$ \\
CPP & $24.1 \pm 0.8^{\mathrm{c}}$ & $-16.4 \pm 0.3^{\mathrm{c}}$ \\
CPP +F & $17.4 \pm 0.8^{\mathrm{d}}$ & $-19.4 \pm 0.3^{\mathrm{d}}$ \\
p-value & $<0.0001$ & $<0.0001$ \\
\hline
\end{tabular}

Negative control: salivary pellicle-coated HA; Heat-inactivated CPP, CPP and CPP + F: salivary pellicle-coated HA modified by heat-inactivated $2.5 \%$ CPP, $2.5 \%$ CPP, and $2.5 \%$ CPP supplemented with 900 ppm fluoride. Data are expressed as the mean \pm SD. Within columns (water contact angle or zeta potential), different superscript letters $(a, b, c, d)$ indicated significant difference $(p<0.05)$ different chemical compositions and unclear previous history [37, 38] which may affect bacterial adhesion to enamel surface [39]. Hence, the HA disc, which is the major component of enamel, was used as the model substrate in the present study. Initial adhesion times of 30 min and $2 \mathrm{~h}$ were chosen to better understand the nonspecific and specific interactions between S. mutans and the substrate [7]. Our results demonstrated that CPP inhibited the initial adhesion of $S$. mutans to s-HA in a dose-dependent manner; a concentration of $2.5 \%$ CPP reduced the adhesion of $S$. mutans by approximately $50 \%$, and this CPP concentration was selected for the current study [31]. The presence of endogenous calcium in the $2.5 \%$ CPP solution could be related to the fact that the CPP is produced by the proteolytic digestion of bovine casein followed with aggregation induced by calcium salt [24]. Fluoride is commonly added to various oral care products. To investigate the effect of fluoride on the efficacy of CPP, a commonly used concentration of fluoride (900 ppm) was selected for incorporation into CPP [40].

The present study indicated that initial adhesion of $S$. mutans to s-HA was inhibited after pellicle modification by CPP and fluoride-doped CPP, and the inhibitory effect of fluoride-doped CPP was most obvious. S-HA modified by heat-inactivated CPP did not appear inhibitory effect on the initial adhesion of $S$. mutans, indicating that denaturing CPP eliminated the anti-adhesion activity. The live-dead staining analysis provides evidence that the anti-adhesion effect of CPP and fluoridedoped CPP was non-bactericidal, namely S. mutans was prevented from attaching to the modified s-HA surface rather than being killed after adhesion. This nonbactericidal therapeutic approach targeting at bacterial adhesion can avoid the selective pressure on microorganisms which may induce resistance to treatment or proliferation of opportunistic pathogens [41].

CPP adsorption and bacterial adhesion to the pellicle are both driven by specific and non-specific interactions, such as electrostatic and hydrophobic interactions [3, 42]. To investigate the effect of pellicle modification by CPP and fluoride-doped CPP on surface properties, the zeta potential and water contact angle were measured to evaluate the charge and hydrophobicity of the s-HA 


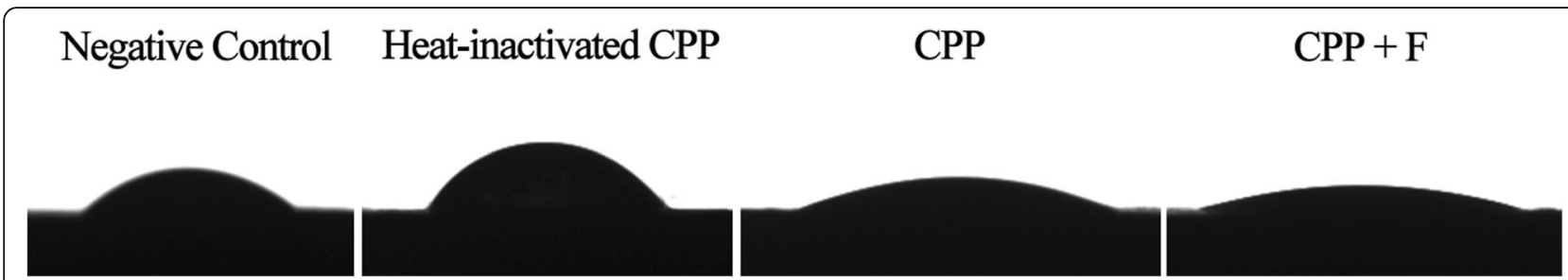

Fig. 4 Representative images showing the contact angle of deionized water on the HA surface with different coatings: salivary pellicle-coated HA (negative control), salivary pellicle-coated HA modified by heat-inactivated 2.5\% CPP (heat-inactivated CPP), or 2.5\% CPP (CPP), or 2.5\% CPP supplemented with 900 ppm fluoride (CPP + F)

surface before and after pellicle modification. Surface charge and hydrophobicity of the substrate are two important determinants that influence bacterial adhesion [43]. Decreased surface hydrophobicity is correlated with decreased bacterial adhesion [44], because initial bacterial adhesion involves the interaction between hydrophobic components on the surface of bacteria and those on the substrate [45]. Increasing the net negative charge of tooth surface reduces Streptococcal adhesion [46], because Streptococcal species (e.g., S. mutans) typically have a negatively charged surface [47]. The present study showed that both zeta potential and water contact angle decreased after pellicle modification by CPP. This suggested that the formation of a more hydrophilic and negatively charged surface increased the repulsion between $S$. mutans and the substrate. CPP is an amphiphiles and negatively charged peptide [24, 48]. A putative underlying mechanism mediating adsorption of CPP to pellicle is the localization of its hydrophobic sites to the pellicle surface and the orientation of hydrophilic sites toward the outer environment, thereby increasing the hydrophilicity and net negative charge of s-HA surface. This is the first study demonstrating that CPP can increase the hydrophilicity and net negative charge of sHA surface, and this synergistic effect partially led to the reduction of $S$. mutans initial adhesion. Although the caries-preventive activity of CPP is known to be mediated by its ability to stabilize high concentrations of ACP on the tooth surface, the anti-adhesion activity of $\mathrm{CPP}$ demonstrated in the present study may be partially responsible for its caries-preventive effect.

Our results also showed that the anti-adhesion effect of fluoride-doped CPP was more efficient than that of $\mathrm{CPP}$, attributing to the lowest water contact angle and zeta potential values found in the fluoride-doped CPP modified s-HA surface. Fluoride inhibits the adhesion of Streptococcus sanguis to the s-HA surface even at low concentrations [49]. The considerable amount of free fluoride (258.4 ppm) in the fluoride-doped CPP solution may play a role in inhibiting $S$. mutans adhesion by further decreasing the negative charge and hydrophobicity of the s-HA surface $[40,50]$. The bound fluoride $(641$ ppm) may have increased the net negative charge of CPP and s-HA surface modified by fluoride-doped CPP. In general, CPP combined with fluoride enhances the anti-adhesion effect.

The present study is limited in that a single bacterial strain was investigated, and the impact of other strains was not assessed. The effects on a greater number of bacterial species should be assessed in future studies.

\section{Conclusions}

The results of this study demonstrated that initial adhesion of $S$. mutans to s-HA can be effectively inhibited by pellicle modification by CPP, and incorporating fluoride into CPP enhances the anti-adhesion effect. We propose, for the first time, that the anti-adhesion effect of CPP and fluoride-doped CPP is non-bactericidal, and that it is mediated, at least in part, by their effect on the nonspecific interactions (electrostatic and hydrophobic interactions) between S. mutans and s-HA.

\section{Supplementary information}

Supplementary information accompanies this paper at https://doi.org/10. 1186/s12903-020-01158-8.

Additional file 1. The optical density $\left(\mathrm{OD}_{562 \mathrm{~nm}}\right)$ of adsorbed proteins/ peptides on the HA discs with different coatings. The data provided include the methods of measuring the amount of adsorbed proteins/ peptides on the HA disc and the corresponding results.

\section{Abbreviations}

CPP: Casein phosphopeptide; S. mutans: Streptococcus mutans; S. sobrinus: Streptococcus sobrinus; CPP-ACP: Casein phosphopeptideamorphous calcium phosphate; BHI: Brain heart infusion; PBS: Phosphate buffered saline; HA: Hydroxyapatite; s-HA: Salivary pellicle-coated hydroxyapatite; CFU: Colony forming units; SEM: Scanning electron microscopy; CLSM: Confocal laser scanning microscopy; Pl: Propidium iodide; SD: Standard deviation (SD)

\section{Acknowledgements}

Not applicable.

\section{Authors' contributions}

HG and JG designed the study. XW performed the experiments and collected the data. $L L, X Z$ and $Y H$ analysed the data. XW and $L L$ wrote the manuscript. $X Z, Y H, J G$, and $H G$ revised the manuscript. All authors have read and approved the final manuscript. 


\section{Funding}

This work was supported by grants from Open Fund of Guangdong Provincial Key Laboratory of Oral Diseases, Sun Yat-sen University (grant number KF2017120102), and Youth Program of National Natural Science Foundation of China (grant number 81700983).

\section{Availability of data and materials}

The datasets used and/or analyzed during the current study are available from the corresponding author on reasonable request.

\section{Ethics approval and consent to participate}

Ethics approval for saliva collection was obtained from the Ethical Review Committee, Hospital of Stomatology, Guanghua School of Stomatology, Sun Yat-sen University (Approval No. ERC-[2017]-24), and written informed consent was obtained from the donors.

\section{Consent for publication}

Not applicable.

\section{Competing interests}

The authors declare that they have no competing interests.

\section{Author details}

${ }^{1}$ Hospital of Stomatology, Guanghua School of Stomatology, Sun Yat-sen University, 56 Ling Yuan Xi Road, Guangzhou 510055, Guangdong, China. ${ }^{2}$ Guangdong Provincial Key Laboratory of Oral Diseases, Sun Yat-sen University, 56 Ling Yuan Xi Road, Guangzhou 510055, Guangdong, China. ${ }^{3}$ School of Dentistry, Faculty of Medicine and Health, The University of Sydney, Camperdown, NSW, Australia. ${ }^{4}$ Institute of Dental Research, Westmead Centre for Oral Health, Westmead, NSW, Australia.

Received: 29 February 2020 Accepted: 3 June 2020

Published online: 12 June 2020

\section{References}

1. Selwitz RH, Ismail Al, Pitts NB. Dental caries. Lancet. 2007;369:51-9.

2. Takahashi N, Nyvad B. The role of bacteria in the caries process: ecological perspectives. J Dent Res. 2011;90:294-303.

3. Hannig $M$, Joiner $A$. The structure, function and properties of the acquired pellicle. Monogr Oral Sci. 2006;19:29-64.

4. Douglas CW. Bacterial-protein interactions in the oral cavity. Adv Dent Res. 1994;8:254-62

5. Loesche WJ. Role of Streptococcus mutans in human dental decay. Microbiol Rev. 1986:50:353-80.

6. Klemm P, Vejborg RM, Hancock V. Prevention of bacterial adhesion. Appl Microbiol Biotechnol. 2010;88:451-9.

7. Cheaib Z, Rakmathulina E, Lussi A, Eick S. Impact of acquired pellicle modification on adhesion of early colonizers. Caries Res. 2015:49:626-32.

8. Hertel S, Potschke S, Basche S, Delius J, Hoth-Hannig W, Hannig M, Hannig C. Effect of tannic acid on the protective properties of the in situ formed pellicle. Caries Res. 2017;51:34-45.

9. Habluetzel A, Schmid C, Carvalho TS, Lussi A, Eick S. Impact of honey on dental erosion and adhesion of early bacterial colonizers. Sci Rep. 2018;8: 10936.

10. Meisel H, Bernard H, Fairweather-Tait S, FitzGerald RJ, Hartmann R, Lane CN, McDonagh D, Teucher B, Wal JM. Detection of caseinophosphopeptides in the distal ileostomy fluid of human subjects. Br J Nutr. 2003;89:351-9.

11. Baum F, Ebner J, Pischetsrieder M. Identification of multiphosphorylated peptides in milk. J Agric Food Chem. 2013;61:9110-7.

12. Dallas DC, Citerne F, Tian T, Silva VL, Kalanetra KM, Frese SA, Robinson RC, Mills DA, Barile D. Peptidomic analysis reveals proteolytic activity of kefir microorganisms on bovine milk proteins. Food Chem. 2016;197:273-84.

13. Reynolds EC. The prevention of sub-surface demineralization of bovine enamel and change in plaque composition by casein in an intra-oral model. J Dent Res. 1987;66:1120-7.

14. Nongonierma $A B$, Fitzgerald RJ. Biofunctional properties of caseinophosphopeptides in the oral cavity. Caries Res. 2012;46:234-67.

15. White AJ, Gracia LH, Barbour ME. Inhibition of dental erosion by casein and casein-derived proteins. Caries Res. 2011;45:13-20.

16. Elgamily H, Safwat E, Soliman Z, Salama H, El-Sayed H, Anwar M. Antibacterial and Remineralization efficacy of casein Phosphopeptide,
Glycomacropeptide Nanocomplex, and probiotics in experimenta toothpastes: an in vitro comparative study. Eur J Dent. 2019;13:391-8.

17. Rao SK, Bhat GS, Aradhya S, Devi A, Bhat M. Study of the efficacy of toothpaste containing casein phosphopeptide in the prevention of dental caries: a randomized controlled trial in 12- to 15-year-old high caries risk children in Bangalore, India. Caries Res. 2009:43:430-5.

18. Rechmann P, Bekmezian S, Rechmann BMT, Chaffee BW, Featherstone JDB. $\mathrm{MI}$ varnish and $\mathrm{Ml}$ paste plus in a caries prevention and remineralization study: a randomized controlled trial. Clin Oral Investig. 2018;22:2229-39.

19. Reynolds EC. Anticariogenic complexes of amorphous calcium phosphate stabilized by casein phosphopeptides: a review. Spec Care Dentist. 1998;18:8-16.

20. Dashper SG, Catmull DV, Liu SW, Myroforidis H, Zalizniak I, Palamara JE, Huq NL, Reynolds EC. Casein phosphopeptide-amorphous calcium phosphate reduces Streptococcus mutans biofilm development on glass lonomer cement and disrupts established biofilms. PLoS One. 2016;11:e0162322.

21. Schupbach P, Neeser JR, Golliard M, Rouvet M, Guggenheim B. Incorporation of caseinoglycomacropeptide and caseinophosphopeptide into the salivary pellicle inhibits adherence of mutans streptococci. J Dent Res. 1996;75:1779-88.

22. Clarkson J, McLoughlin J. Role of fluoride in oral health promotion. Int Dent J. 2000;50:119-28.

23. Nassar HM, Gregory RL. Biofilm sensitivity of seven Streptococcus mutans strains to different fluoride levels. J Oral Microbiol. 2017;9:1328265.

24. FitzGerald RJ. Potential uses of Caseinophosphopeptides. Int Dairy J. 1998:8:451-7.

25. Sinfiteli PP, Coutinho TCL, Oliveira PRA, Vasques WF, Azevedo LM, Pereira $A M B$, Tostes MA. Effect of fluoride dentifrice and casein phosphopeptideamorphous calcium phosphate cream with and without fluoride in preventing enamel demineralization in a pH cyclic study. J Appl Oral Sci. 2017:25:604-11.

26. Hamba H, Nikaido T, Inoue G, Sadr A, Tagami J. Effects of CPP-ACP with sodium fluoride on inhibition of bovine enamel demineralization: a quantitative assessment using micro-computed tomography. J Dent. 2011; 39:405-13.

27. Poggio C, Gulino C, Mirando M, Colombo M, Pietrocola G. Preventive effects of different protective agents on dentin erosion: an in vitro investigation. J Clin Exp Dent. 2017:9:e7-e12.

28. Wiegand A, Attin T. Randomised in situ trial on the effect of milk and CPPACP on dental erosion. J Dent. 2014:42:1210-5.

29. Bhattarai KR, Kim HR, Chae HJ. Compliance with saliva collection protocol in healthy volunteers: strategies for managing risk and errors. Int J Med Sci. 2018;15:823-31.

30. Jakubovics NS, Robinson JC, Samarian DS, Kolderman E, Yassin SA, Bettampadi D, Bashton M, Rickard AH. Critical roles of arginine in growth and biofilm development by Streptococcus gordonii. Mol Microbiol. 2015; 97:281-300.

31. Li BC, Li XL, Lin HC, Zhou Y. Curcumin as a promising antibacterial agent: effects on metabolism and biofilm formation in S. mutans. Biomed Res Int 2018;2018:4508709. Published 2018 Feb 28. https://doi.org/10.1155/2018/ 4508709.

32. Fernando JR, Shen P, Sim CPC, Chen YY, Walker GD, Yuan Y, Reynolds C, Stanton DP, MacRae CM, Reynolds EC. Self-assembly of dental surface nanofilaments and remineralisation by SnF2 and CPP-ACP nanocomplexes. Sci Rep. 2019:9:1285.

33. Marine J, Myers CP, Picquet GA, Zaidel LA, Wu D, Uhrich KE. Reduction of bacterial attachment on hydroxyapatite surfaces: using hydrophobicity and chemical functionality to enhance surface retention and prevent attachment. Colloids Surf B: Biointerfaces. 2018;167:531-7.

34. Bezerra SJC, Joao-Souza SH, Aoki IV, Borges AB, Hara AT, Scaramucci T. Antierosive effect of solutions containing sodium fluoride, stannous chloride, and selected film-forming polymers. Caries Res. 2019;53:305-13.

35. Gibbons RJ. Adherent interactions which may affect microbial ecology in the mouth. J Dent Res. 1984:63:378-85.

36. Campoccia D, Montanaro L, Arciola CR. A review of the biomaterials technologies for infection-resistant surfaces. Biomaterials. 2013;34:8533-54

37. Weatherell JA, Deutsch D, Robinson C, Hallsworth AS. Fluoride concentrations in developing enamel. Nature. 1975:256:230-2.

38. Weatherell JA, Robinson C, Hallsworth AS. Variations in the chemical composition of human enamel. J Dent Res. 1974:53:180-92. 
39. McConnell MD, Liu Y, Nowak AP, Pilch S, Masters JG, Composto RJ. Bacterial plaque retention on oral hard materials: effect of surface roughness, surface composition, and physisorbed polycarboxylate. J Biomed Mater Res A. 2010; 92:1518-27.

40. Loskill P, Zeitz C, Grandthyll S, Thewes N, Muller F, Bischoff M, Herrmann M, Jacobs K. Reduced adhesion of oral bacteria on hydroxyapatite by fluoride treatment. Langmuir. 2013;29:5528-33.

41. Davies J, Davies D. Origins and evolution of antibiotic resistance. Microbiol Mol Biol Rev. 2010;74:417-33.

42. Huq NL, Myroforidis H, Cross K, Stanton DP, Veith PD, Ward BR, Reynolds EC. The interactions of CPP-ACP with saliva. Int J Mol Sci. 2016;17:915.

43. Song $\mathrm{F}, \mathrm{Koo} \mathrm{H}$, Ren D. Effects of material properties on bacterial adhesion and biofilm formation. J Dent Res. 2015;94:1027-34.

44. Yang $X$, Huang $P$, Wang H, Cai S, Liao Y, Mo Z, Xu X, Ding C, Zhao C, Li J. Antibacterial and anti-biofouling coating on hydroxyapatite surface based on peptide-modified tannic acid. Colloids Surf B: Biointerfaces. 2017;160: 136-43.

45. Colloca ME, Ahumada MC, Lopez ME, Nader-Macias ME. Surface properties of lactobacilli isolated from healthy subjects. Oral Dis. 2000;6:227-33.

46. Reynolds EC, Wong A. Effect of adsorbed protein on hydroxyapatite zeta potential and Streptococcus mutans adherence. Infect Immun. 1983;39: 1285-90.

47. Roger V, Tenovuo J, Lenander-Lumikari M, Soderling E, Vilja P. Lysozyme and lactoperoxidase inhibit the adherence of Streptococcus mutans NCTC 10449 (serotype c) to saliva-treated hydroxyapatite in vitro. Caries Res. 1994; 28:421-8.

48. Cross K, Huq NL, Palamara JE, Perich JW, Reynolds EC. Physicochemical characterization of casein phosphopeptide-amorphous calcium phosphate nanocomplexes. J Biol Chem. 2005;280:15362-9.

49. Eifert R, Rosan B, Golub E. Optimization of an hydroxyapatite adhesion assay for Streptococcus sanguis. Infect Immun. 1984;44:287-91.

50. de Jong HP, de Boer P, van Pelt AW, Busscher HJ, Arends J. Effect of topically applied fluoride solutions on the surface free energy of pelliclecovered human enamel. Caries Res. 1984;18:505-8.

\section{Publisher's Note}

Springer Nature remains neutral with regard to jurisdictional claims in published maps and institutional affiliations.

Ready to submit your research? Choose BMC and benefit from:

- fast, convenient online submission

- thorough peer review by experienced researchers in your field

- rapid publication on acceptance

- support for research data, including large and complex data types

- gold Open Access which fosters wider collaboration and increased citations

- maximum visibility for your research: over $100 \mathrm{M}$ website views per year

At BMC, research is always in progress.

Learn more biomedcentral.com/submissions 